\title{
Assessing forces during spinal manipulation and mobilization: factors influencing the difference between forces at the patient- table and clinician-patient interfaces
}

\author{
Jérémie Mikhail ${ }^{1}$, Martha Funabashi ${ }^{1,2}$, Martin Descarreaux $^{3}$ and Isabelle Pagé (1, $^{*}$ (D)
}

\begin{abstract}
Background: Spinal manipulative therapy (SMT) and mobilization (MOB) effects are believed to be related to their force characteristics. Most previous studies have either measured the force at the patient-table interface or at the clinician-patient interface. The objectives of this study were to determine 1) the difference between the force measured at the patient-table interface and the force applied at the clinician-patient interface during thoracic SMT and $M O B$, and 2) the influence of the SMT/MOB characteristics, participants' anthropometry and muscle activity (sEMG) on this difference.
\end{abstract}

Methods: An apparatus using a servo-linear motor executed 8 SMT/MOB at the T7 vertebrae in 34 healthy adults between May and June 2019. SMT and MOB were characterized by a $20 \mathrm{~N}$ preload, total peak forces of $100 \mathrm{~N}$ or $200 \mathrm{~N}$, and thrust durations of $100 \mathrm{~ms}, 250 \mathrm{~ms}$, 1 s or 2 s. During each trial, thoracic sEMG, apparatus displacement as well as forces at the patient-table interface and the clinician-patient interface were recorded. The difference between the force at both interfaces was calculated. The effect of SMT/MOB characteristics on the difference between forces at both interfaces and correlations between this difference and potential influencing factors were evaluated.

Results: Force magnitudes at the patient-table interface were, in most trials, greater than the force at the clinicianpatient interface (up to $135 \mathrm{~N}$ ). SMT/MOB characteristics (total peak force, thrust duration and rate of force application) affected the difference between forces at both interfaces (all $p$-values< 0.05 ). No factor showed significant correlations with the difference between forces at both interfaces for the 8 SMT/MOB.

Conclusions: The results revealed that the force measured at the patient-table interface is greater than the applied force at the clinician-patient interface during thoracic SMT and MOB. By which mechanism the force is amplified is not yet fully understood.

Keywords: Force, Kinetics, Spinal manipulative therapy, Thoracic spine

\footnotetext{
* Correspondence: isabelle.page1@uqtr.ca

'Department of Chiropractic, Université du Québec à Trois-Rivières, 3351

boul. Des Forges, Trois-Rivières G8Z 4M3, Québec, Canada

${ }^{4}$ Center for Interdisciplinary Research in Rehabilitation and Social Integration

(CIRRIS), 25 Wilfrid-Hamel Blvd., Québec G1M 2S8, Québec, Canada

Full list of author information is available at the end of the article
}

C C The Author(s). 2020 Open Access This article is licensed under a Creative Commons Attribution 4.0 International License, which permits use, sharing, adaptation, distribution and reproduction in any medium or format, as long as you give appropriate credit to the original author(s) and the source, provide a link to the Creative Commons licence, and indicate if changes were made. The images or other third party material in this article are included in the article's Creative Commons licence, unless indicated otherwise in a credit line to the material. If material is not included in the article's Creative Commons licence and your intended use is not permitted by statutory regulation or exceeds the permitted use, you will need to obtain permission directly from the copyright holder. To view a copy of this licence, visit http://creativecommons.org/licenses/by/4.0/. The Creative Commons Public Domain Dedication waiver (http://creativecommons.org/publicdomain/zero/1.0/) applies to the data made available in this article, unless otherwise stated in a credit line to the data. 


\section{Introduction}

Spinal manipulative therapy (SMT) and spinal mobilization (MOB) are commonly used by several health care professionals in the management of musculoskeletal conditions [1]. SMT is characterized by the application of a dynamic force using a high-velocity and low-amplitude thrust, whereas $\mathrm{MOB}$ is defined by the application of a cyclic and rhythmic low-velocity force to the intervertebral joint. Forces, from both interventions, cause a mechanical deformation of the spinal region and surrounding tissues and are believed to trigger neuromechanical responses that potentially contribute to their respective therapeutic effects [2-4].

The quantification of SMT and MOB forces has been the focus of several studies and is fundamental to better understanding the underlying biomechanical mechanism in which SMT and MOB act on the body. Although previous studies have investigated the forces applied during SMT and MOB, most studies have focused on the characteristics of the reaction forces (at the patienttable interface) or forces directly applied to the patient (at the clinician-patient interface) [5-7]. A systematic review by Downie et al. (2010) showed that forces measured at the patient-table interface reach on average $1044 \mathrm{~N}( \pm 186 \mathrm{~N})$ and that applied peak forces at clinician-patient interface during thoracic SMT vary between $238 \mathrm{~N}$ and $561 \mathrm{~N}$ [8]. For MOB, a systematic review by Snodgrass et al. (2006) showed that forces vary greatly as a function of the mobilization grade, with measured forces at the patient-table interface during thoracic MOB grade IV ranging from $232 \mathrm{~N}$ to $500 \mathrm{~N}$ [7].

Nevertheless, to elucidate SMT and MOB biomechanical underlying therapeutic mechanisms, it is fundamental to understand all forces acting on the body during the application of these interventions and how they interact with each other. Forces at both the patient-table interface and the clinician-patient interface have only been measured concomitantly by Kirstukas \& Backman (1999) [5]. Based on mathematical models and given the deformable behaviour of the human body during dynamic loading application, forces at the patient-table interface were expected to be larger than the forces applied at the clinician-patient interface. Results from this study, however, showed that the peak forces at the patient-table interface were, on average, $16 \%$ lower than the peak forces at the clinician-table interface. Limitations related to the measurement instruments used in the study were outlined by the authors.

New investigative tools are now available, and limitations reported previously can now be addressed. Specifically, at the clinician-patient interface, a servocontroller linear actuator motor capable of applying SMT and MOB with repeatable and standardized forces was developed [9], significantly advancing the investigation of SMT and MOB applied forces (ex. Pagé et al. 2014;2018 [10, 11] and Nougarou et al. 2013;2014 [12, 13]). On the other hand, the Force Sensing Table Technology $\left(\mathrm{FSTT}^{\circ}\right)$ accurately measures the forces at the patient-table interface [14]. By combining these two technologies, more accurate measurements and comparisons of forces at both interfaces during SMT and MOB are possible. Furthermore, other factors such as the technique parameters (total peak force magnitude and rate of force application) and the person receiving the SMT or MOB (age, percentage body fat, thorax thickness and muscle activation during technique application) can potentially influence the magnitude of the difference between forces at both interfaces during SMT and MOB. A better understanding of such interplay will further significant knowledge related to SMT and MOB biomechanics and potentially reveal important information related to underlying physiological mechanisms of manual therapy. Moreover, the results could guide the development of futures studies assessing SMT/MOB characteristics.

Therefore, this study aimed to 1) quantify the difference between the forces measured at the patient-table interface and the force applied at the clinician-patient interface during standardized thoracic SMT and MOB in asymptomatic adults and 2) to explore the factors related to SMT/MOB force characteristics and participant characteristics that potentially influence the magnitude of this difference. Based on the deformable behaviour of the human body and the viscoelastic properties of biological tissues, it was hypothesized that the forces measured at the patient-table interface would be greater than the force applied at the clinician-patient interface. It was also hypothesized that the difference in force between both interfaces would vary as a function of the SMT/MOB characteristics, muscle activation, and participant's body composition.

\section{Methods \\ Participants}

Adults without thoracic pain and aged between 18 and 50 years old were recruited through advertisement on social media and word of mouth between May and June 2019. Participants were excluded if they presented any contraindication to SMT and MOB [15], had a history of spine surgery, vertebral fracture or were diagnosed with a spine infection, osteopenia or thoracic scoliosis. The study was approved by the Université du Québec à Trois-Rivières human research ethics committee (CER-19-257-07.19) and all participants provided their written informed consent prior to participating in the study. 


\section{Protocol summary}

Participants were invited to take part in two 60-min experimental sessions conducted 2 to 4 days apart. During the first sessions, participants' age, sex and anthropometry (height, weight, thorax thickness and percentage of body and trunk fat) were obtained.

Participants were asked to lie prone on a force-sensing table technology $\left(\mathrm{FSTT}^{\circ}\right.$, detailed below) and $\mathrm{T} 5, \mathrm{~T} 6$ and T7 spinous processes were identified by palpation. T7 transverse processes were also identified using the landmarks suggested by Cooperstein et al. (2009) [16] and Pagé et al. (2017) [17]. Surface electromyography (EMG) electrodes were then placed on the skin overlying the thoracic erector spinae (TES) muscles, and a normalization trial was performed. While the participant was lying in prone position, two $1.14 \mathrm{~kg}$ weights were placed on a wood stool on each side of the participant's head. Participants were then instructed to take a weight in each hand and lift them just over the support and hold for $5 \mathrm{~s}$ while EMG signals were recorded.

The apparatus used to deliver SMT and MOB (detailed below) was then positioned on the participant's back with its rod tip aligned with $\mathrm{T} 7$ transverse processes. T7 was chosen for all participants to limit the impact of the spine curvature as it has been described to be commonly the apical vertebrae of the thoracic kyphosis [18]. A total of four SMT and four MOB with different force-time characteristics were delivered over the two sessions using a randomized order (four per session). During each technique application, muscle activity, rod displacement, forces at the patient-table interfaces and the apparatus-patient interface (further referred as the clinician-patient interface to ease comparison with previous literature) were respectively recorded by the surface EMG electrodes, the $\mathrm{FSTT}^{\bullet}$ and the apparatus.

\section{Instrumentation}

\section{Anthropometric measurements}

Height was measured using a tape mounted on the wall while weight and percentage of body and trunk fat was assessed using a bioelectrical impedance scale (Segmental Body Composition Analyzer, Tanita BC-418). A caliper (S\&S X-Ray Products Inc. Brooklyn, NY, error \pm 0.5 $\mathrm{cm})$ was used to measure the thorax thickness, defined as the distance between the skin at the level of T7 spinous process and the surface of the $\mathrm{FSTT}^{\bullet}$ when the participant was lying in prone.

\section{Force-sensing table}

A force-sensing treatment table was used to measure the forces at the anterior aspect of the thorax (patient-table interface) during each SMT and MOB. The Force Sensing Table Technology (FSTT ${ }^{\oplus}$, Toronto, Ontario, Canada) is composed of a treatment table and an integrated AMTI force plate (Advanced Mechanical Technology Inc., Watertown, Massachusetts, USA). The $\mathrm{FSTT}^{\circ}$ has been shown to be reliable in the measurement of SMT force-time characteristics [14]. The 3dimensional force plate voltages in $\mathrm{Fx}, \mathrm{Fy}$ and $\mathrm{Fz}$ were recorded at $1 \mathrm{kHz}$ with a 12 -bit $\mathrm{A} / \mathrm{D}$ converter.

\section{Surface electromyography (EMG)}

Four bipolar surface EMG electrodes $(10 \mathrm{~mm}$ interelectrode distance, Delsys, Inc., Boston, MA) were used to record TES muscle activity during each SMT and MOB application. Electrodes were applied bilaterally at approximately $2 \mathrm{~cm}$ laterally of the $\mathrm{T} 5$ and $\mathrm{T} 7$ spinous processes in line with TES muscle fibers. A reference electrode was applied on the left lateral malleolus. Prior to electrode placement, the skin was shaved, slightly abraded and cleaned with alcohol swabs to reduce impedance. Data were recorded at $1 \mathrm{kHz}$ with a 12-bit A/D converter. EMG and forces (at the clinician-patient and patient-table interfaces) data acquisitions were synchronized.

\section{Manual technique application}

An apparatus using a servo-controlled linear actuator motor (Linear Motor Series P01-48 × 360, LinMot Inc., Zurich, Switzerland) was used to deliver standardized SMT and MOB. This apparatus has both high repeatability and precision in delivering standardized SMT and MOB forces [9]. The apparatus indenter consisted of a twin-tip padded $\operatorname{rod}(\theta$ tip $=10 \mathrm{~mm}$; distance between the center of the tips $=56 \mathrm{~mm}$ ) positioned on the skin overlying the T7 transverse processes. Accurate repositioning of the device was ensured by marking the location of the twin-tip with an ink pen at the end of the first session.

Figure 1 shows examples of typical SMT and MOB force-time graphs, while Table 1 presents the force-time characteristics of the four SMT and four MOB applied in the current study. The force-time characteristics used in this study were based on data reported in the literature $[7,8]$. Specifically, SMT and MOB were characterized by a $20 \mathrm{~N}$ preload force maintained during $1 \mathrm{~s}$, followed by a total peak force of 100 or 200 N. For SMT, thrust durations were of 100 or $250 \mathrm{~ms}$ and the total peak force was immediately removed once reached. For $\mathrm{MOB}$, thrust durations were of 1 or $2 \mathrm{~s}$ and the total peak force was maintained for the same duration as the thrust duration before being removed. The displacement of the twin-tip indenter $(\mathrm{mm})$ and the force $(\mathrm{N})$ generated by the apparatus during the SMT and MOB were recorded using LinMot-Talk ${ }^{\bullet}$ software (version 5.1, LinMot Inc., Zurich, Switzerland) at a frequency of $256 \mathrm{~Hz}$.

Both SMT and MOB were performed 5 min apart during which participants rested quietly on the treatment 


\section{A. Spinal manipulative therapy}

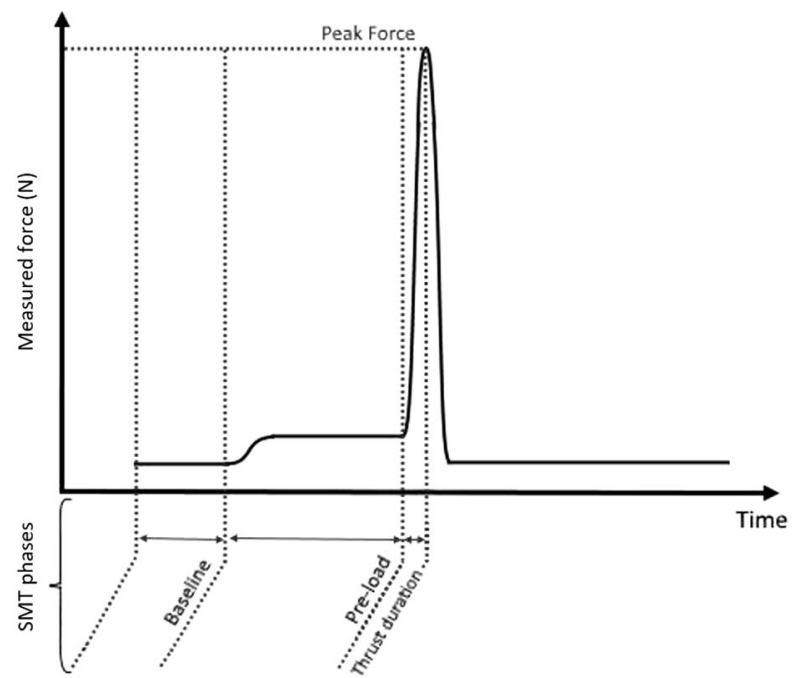

B. Spinal mobilization

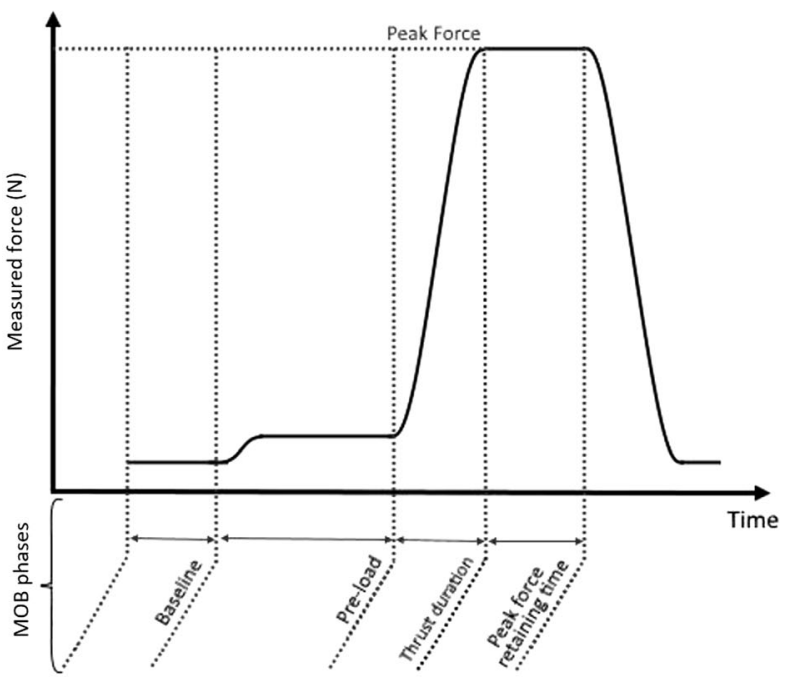

Fig. 1 Force-time graphs of a typical (a) spinal manipulative therapy and (b) spinal mobilization

table. To avoid soreness and tiredness, the eight applications were delivered over two sessions. The order of the force-time characteristics was randomly determined to minimize any sequential effect. At the start of the second session ( 2 to 4 days later), absence of pain in the thoracic region was confirmed by asking the participants to complete a 11-point visual analog scale for the assessment of pain [19]. If a score of 2 or greater was noted, the session was postponed for $24 \mathrm{~h}$.

\section{Data processing and analysis}

\section{Calculation of the difference in force between interfaces}

For each trial, the difference of force between the preload and the total peak force was calculated for data measured at both the patient-table interface (FSTT ${ }^{\circ}$ table data) and the clinician-patient interface (apparatus data). Since the FSTT ${ }^{\circ}$ measures forces in the three axes of motion ( $\mathrm{Fx}, \mathrm{Fy}$ and $\mathrm{Fz}$ ), the overall force at the patient-table interface $\left(\mathrm{F}_{\mathrm{PTint}}\right)$ was calculated. The difference in the force obtained at both interfaces $\left(\mathrm{F}_{\text {diff }}\right)$ was then computed with a positive $\mathrm{F}_{\text {diff }}$ corresponding to a greater force at the patient-table interface than the applied force at the clinician-patient interface. The FSTT ${ }^{\circ}$ coordinate system and $\mathrm{F}_{\text {diff }}$ formula are respectively presented in Fig. 2a and b.

\section{EMG data processing}

EMG data were first digitally band-pass filtered (20-450 $\mathrm{Hz}$ ). For each SMT and MOB, the surface EMG signal was synchronized with the apparatus' force data to determine the time-window from the start of the thrust to the total peak force. Muscle activity amplitude (root mean square, RMS) was then calculated for the four surface EMG electrodes and each electrode's RMS value

Table 1 Biomechanical characteristics of the four SMT and four MOB

\begin{tabular}{llllll}
\hline $\begin{array}{l}\text { Force-time } \\
\text { profiles }\end{array}$ & $\begin{array}{l}\text { Preload force } \\
(\mathbf{N})\end{array}$ & $\begin{array}{l}\text { Total peak force } \\
(\mathbf{N})\end{array}$ & $\begin{array}{l}\text { Thrust duration } \\
(\mathbf{m s})\end{array}$ & $\begin{array}{l}\text { Total peak force retaining time } \\
(\mathbf{m s})\end{array}$ & $\begin{array}{l}\text { Rate of force application } \\
(\mathbf{N} / \mathbf{s})\end{array}$ \\
\hline SMT1 & 20 & 100 & 100 & 0 & 800 \\
SMT2 & 20 & 100 & 250 & 0 & 320 \\
SMT3 & 20 & 200 & 100 & 250 & 1800 \\
SMT4 & 20 & 200 & 1000 & 0 & 720 \\
MOB1 & 20 & 100 & 2000 & 1000 & 80 \\
MOB2 & 20 & 100 & 1000 & 2000 & 40 \\
MOB3 & 20 & 200 & 2000 & 1000 & 180 \\
MOB4 & 20 & 200 & 2000 & 90 \\
\hline
\end{tabular}




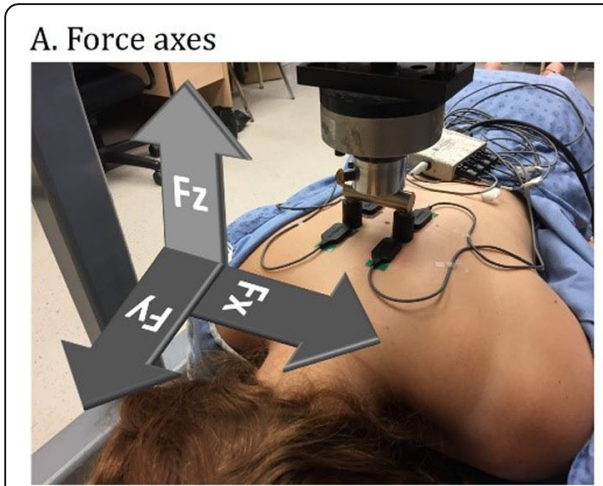

B. Formula

1) $\mathrm{F}_{\mathrm{PTint}}=\sqrt{\left(F x^{2}+F y^{2}+F z^{2}\right)}$

2) $\mathrm{F}_{\text {diff }}=\mathrm{F}_{\mathrm{PTint}}-$ Force at the clinician-patient interface

Fig. 2 a. Apparatus used to deliver SMT and MOB, surface EMG electrodes recording muscle activity and schematization of the FSTT ${ }^{\circledR}$ coordinate system. b. Formula to calculate the difference in force between the patient-table and the clinician-patient interfaces $\left(F_{\text {diff }}\right)$

was further divided by its respective value obtained during the normalization trial. The left and right normalized RMS value (nRMS) of electrodes located at the same spinal level were then averaged (T5 nRMS and T7 nRMS) and used for subsequent analyses.

\section{Statistical analysis}

Main analysis A descriptive analysis of the participants' characteristics was computed. Mean (SD) values are reported for parametric data and median with interquartile range (IQR) for non-parametric data.

A mixed-model ANOVA was computed to assess the effects of the total peak forces (2 levels) and the thrust durations (4 levels) on $\mathrm{F}_{\text {diff. When indicated, the Tukey }}$ post-hoc test was computed to depict the significant differences. A repeated measures ANOVA with planned comparisons for linear trend was also conducted to assess the effect of the rate of force application (8 levels) on $\mathrm{F}_{\text {diff. }}$.

Exploratory analysis For each SMT and MOB forcetime profile (Table 1), exploratory correlations between $F_{\text {diff }}$ and potential factors influencing this difference were computed. Factors included the apparatus rod displacement, participants' anthropometry (weight, height, body mass index [BMI], percentage of body and trunk fat, and thorax thickness) and muscle activity amplitude (T5 nRMS and T7 nRMS). Pearson's correlation coefficient was computed when the factor presented a parametric distribution, while Pearson's estimated value obtained from Kendall Tau B correlation coefficients was computed for nonparametric data distribution. The strength of the correlations was evaluated as "strong" $(\mathrm{r} \geq 0.70)$, "good" $(0.50 \leq r \leq 0.70)$, "moderate" $(0.30 \leq r \leq 0.50)$, or "poor" $(r \leq 0.30)$ [20]. Finally, t-tests for independent samples were used to assess whether $F_{\text {diff }}$ was significantly different between males and females.
Statistical analysis was conducted using Statistica ${ }^{\mathrm{m}}$ (Version 13.3, TIBCO software Inc., USA) with a statistical significance set at $p<0.05$.

\section{Results}

\section{Participants}

Of the 35 participants recruited, one was excluded following the first SMT trial due to pain during the procedure. Data from one additional participant were excluded as it was incomplete. The data of the remaining 33 participants were used for the analyses (Table 2).

\section{Difference in force between both interfaces}

The mean (SD) values of the $F_{\text {diff }}$ are reported in Table 3 for each force-time profile. For most trials, greater forces at the patient-table interface than at the clinician-patient interface were measured.

\section{Effects of the SMT and MOB characteristics}

Mixed-model ANOVAs showed that the thrust duration $\left(\mathrm{F}_{3,96}=13.09, p<0.001, \eta_{p}^{2}=0.29\right)$ and the total peak force $\left(\mathrm{F}_{1,32}=92.73, p<0.001, \eta_{p}^{2}=0.74\right)$ significantly affect $\mathrm{F}_{\text {diff. }}$ The interaction effect between the thrust duration and the total peak force was also significant

Table 2 Participants characteristics

\begin{tabular}{ll}
\hline Characteristics & Value $(\boldsymbol{n}=\mathbf{3 3})$ \\
\hline Females: Males & $18: 15$ \\
Age (years; mean $\pm \mathrm{SD})$ & $24.15 \pm 2.70$ \\
Weight $(\mathrm{kg} ;$ median $\pm \mathrm{IQR})$ & $70.00 \pm 20.70$ \\
Height $(\mathrm{m}$; median $\pm \mathrm{IQR})$ & $1.69 \pm 0.11$ \\
BMI $\left(\mathrm{kg} / \mathrm{m}^{2}\right.$; median $\left.\pm \mathrm{IQR}\right)$ & $24.00 \pm 4.00$ \\
Percentage body fat $(\% ;$ median $\pm \mathrm{IQR})$ & $20.00 \pm 15.30$ \\
Percentage trunk fat $(\% ;$ median $\pm \mathrm{IQR})$ & $19.10 \pm 11.15$ \\
Thorax thickness $(\mathrm{cm} ;$ median $\pm \mathrm{IQR})$ & $19.00 \pm 2.00$ \\
\hline
\end{tabular}


Table 3 Difference between forces at the patient-table interface and the clinician-patient interface ( $\left.F_{\text {diff }}\right)$ for each SMT force-time profile

\begin{tabular}{|c|c|c|c|c|c|}
\hline \multirow{2}{*}{$\begin{array}{l}\text { Force-time } \\
\text { profiles }^{\mathrm{a}}\end{array}$} & \multicolumn{3}{|l|}{$F_{\text {diff }}$} & \multirow{2}{*}{$\begin{array}{l}\text { Participants } \\
\text { showing greater } \\
\text { force at the } \\
\text { patient-table } \\
\text { interface (n) }\end{array}$} & \multirow{2}{*}{$\begin{array}{l}\text { Participants } \\
\text { showing greater } \\
\text { force at the } \\
\text { clinician-patient } \\
\text { interface }(\mathrm{n})\end{array}$} \\
\hline & Mean $^{b}$ & SD & Range & & \\
\hline SMT1 & $15.56 \mathrm{~N}$ & $4.86 \mathrm{~N}$ & $5.35 \mathrm{~N}$ to $26.09 \mathrm{~N}$ & 33 & 0 \\
\hline SMT2 & $4.74 \mathrm{~N}$ & $6.72 \mathrm{~N}$ & $-7.35 \mathrm{~N}$ to $29.06 \mathrm{~N}$ & 26 & 7 \\
\hline SMT3 & $36.70 \mathrm{~N}$ & $10.02 \mathrm{~N}$ & $10.45 \mathrm{~N}$ to $56.82 \mathrm{~N}$ & 33 & 0 \\
\hline SMT4 & $16.74 \mathrm{~N}$ & $14.13 \mathrm{~N}$ & $-8.41 \mathrm{~N}$ to $68.04 \mathrm{~N}$ & 31 & 2 \\
\hline MOB1 & $8.77 \mathrm{~N}$ & $12.34 \mathrm{~N}$ & $-11.22 \mathrm{~N}$ to $57.82 \mathrm{~N}$ & 26 & 7 \\
\hline MOB2 & $7.12 \mathrm{~N}$ & $10.74 \mathrm{~N}$ & $-8.58 \mathrm{~N}$ to $47.10 \mathrm{~N}$ & 26 & 7 \\
\hline MOB3 & $29.23 \mathrm{~N}$ & $28.55 \mathrm{~N}$ & $-4.28 \mathrm{~N}$ to $135.08 \mathrm{~N}$ & 29 & 4 \\
\hline MOB4 & $21.40 \mathrm{~N}$ & $25.24 \mathrm{~N}$ & $-11.39 \mathrm{~N}$ to $130.05 \mathrm{~N}$ & 30 & 3 \\
\hline
\end{tabular}

${ }^{a}$ The list refers to the force-time profiles presented in Table 1

${ }^{b}$ A positive $F_{\text {diff }}$ denotes that the force measured at the patient-table interface was greater than the force measured at the clinician-patient interface

$\left(\mathrm{F}_{3,96}=3.44, p=0.02, \eta_{p}^{2}=0.10\right)$. Results of the Tukey post-hoc tests are presented in Table 4.

Considering the significant interaction between the thrust duration and the total peak force on $\mathrm{F}_{\text {diff, the rate }}$ of force application effect was analysed. The analysis revealed a significant rate of force application main effect $\left(\mathrm{F}_{7,224}=24.61, p<0.001, \eta_{p}^{2}=0.43\right)$. Planned contrasts demonstrated a significant linear decrease in $\mathrm{F}_{\text {diff }}$ with the decrease in rate of force application $\left(\mathrm{F}_{1,32}=28.65\right.$, $p<0.0001$ ) (Fig. 3). Overall, the SMT with the higher rate of force application (SMT3: $1800 \mathrm{~N} / \mathrm{s}$ ) and the MOB with the lower rate of force application (MOB2: $40 \mathrm{~N} / \mathrm{s}$ ) resulted in a mean difference of $29.58 \mathrm{~N}$ (95\% CI: $24.47-$ $34.69 \mathrm{~N}$ ) in $\mathrm{F}_{\text {diff. }}$.

\section{Exploratory analysis}

Table 5 presents the correlations between $F_{\text {diff }}$ and potential influencing factors as well as the differences between males and females. A significantly greater $F_{\text {diff }}$ was observed in females compared to males during SMT1 $\left(\mathrm{T}_{32}=2.14, p=0.04\right)$ with a mean difference of $3.35 \mathrm{~N}(95 \% \mathrm{CI}=0.16$ to $6.54 \mathrm{~N})$. Significant differences between females and males were not observed for the other force-time profiles (all $p$ values $>0.05$ ).

Only four factors showed significant correlations with $\mathrm{F}_{\text {diff }}$ and none presented consistent correlations among the eight force-time profiles. Apparatus' displacement showed significant positive correlation with $\mathrm{F}_{\text {diff }}$ during the two fastest SMTs (SMT1, $r=0.67$, $p=0.001$; SMT3, $\mathrm{r}=0.54, p=0.001$ ). Thoracic thickness was significantly correlated with $F_{\text {diff }}$ during SMT2 $\left(\mathrm{r}_{\mathrm{e}}=-0.36, p=0.049\right)$ and MOB2 $\left(\mathrm{r}_{\mathrm{e}}=-0.53\right.$, $p=0.004)$. Moreover, $\mathrm{F}_{\text {diff }}$ was significantly correlated with muscle activity during SMT4 (T5-nRMS, $\mathrm{r}_{\mathrm{e}}=$ $0.50 p=0.01 ;$ T7-nRMS, $\left.\mathrm{r}_{\mathrm{e}}=0.44 p=0.02\right)$ and MOB3 (T7-nRMS, $\mathrm{r}_{\mathrm{e}}=0.42, p=0.02$ ). No significant correlations between $F_{\text {diff }}$ and the following factors were found for any of the force-time profiles: weight, height, age, BMI, percentage of body fat and percentage of trunk fat (all $p$ values>0.05).

Table 4 Significant differences in $F_{\text {diff }}$ between the force-time profiles

\begin{tabular}{|c|c|c|c|c|c|c|c|}
\hline Force-time profiles & $\begin{array}{l}\text { SMT2 } \\
(\text { mean }=4.74 \mathrm{~N})\end{array}$ & $\begin{array}{l}\text { SMT3 } \\
(36.70 \mathrm{~N})\end{array}$ & $\begin{array}{l}\text { SMT4 } \\
(16.74 \mathrm{~N})\end{array}$ & $\begin{array}{l}\text { MOB1 } \\
(8.77 \mathrm{~N})\end{array}$ & $\begin{array}{l}\text { MOB2 } \\
(7.12 \mathrm{~N})\end{array}$ & $\begin{array}{l}\text { MOB3 } \\
(29.23 \mathrm{~N})\end{array}$ & $\begin{array}{l}\text { MOB4 } \\
(21.40 \mathrm{~N})\end{array}$ \\
\hline SMT1 & $p<0.001^{*}$ & $p<0.001^{*}$ & $p \geq 0.05$ & $p \geq 0.05$ & $p=0.02^{*}$ & $p<0.001^{*}$ & $p \geq 0.05$ \\
\hline SMT2 & & $p<0.001^{*}$ & $p<0.001^{*}$ & $p \geq 0.05$ & $p \geq 0.05$ & $p<0.001^{*}$ & $p<0.001^{*}$ \\
\hline SMT3 & & & $p<0.001^{*}$ & $p<0.001^{*}$ & $p<0.001^{*}$ & $p \geq 0.05$ & $p<0.001^{*}$ \\
\hline SMT4 & & & & $p=0.03^{*}$ & $p=0.004^{*}$ & $p<0.001^{*}$ & $p \geq 0.05$ \\
\hline MOB1 & & & & & $p \geq 0.05$ & $p<0.001^{*}$ & $p<0.001^{*}$ \\
\hline MOB2 & & & & & & $p<0.001^{*}$ & $p<0.001^{*}$ \\
\hline MOB3 & & & & & & & $p=0.04^{*}$ \\
\hline
\end{tabular}

* significant differences at $p<0.05$ 


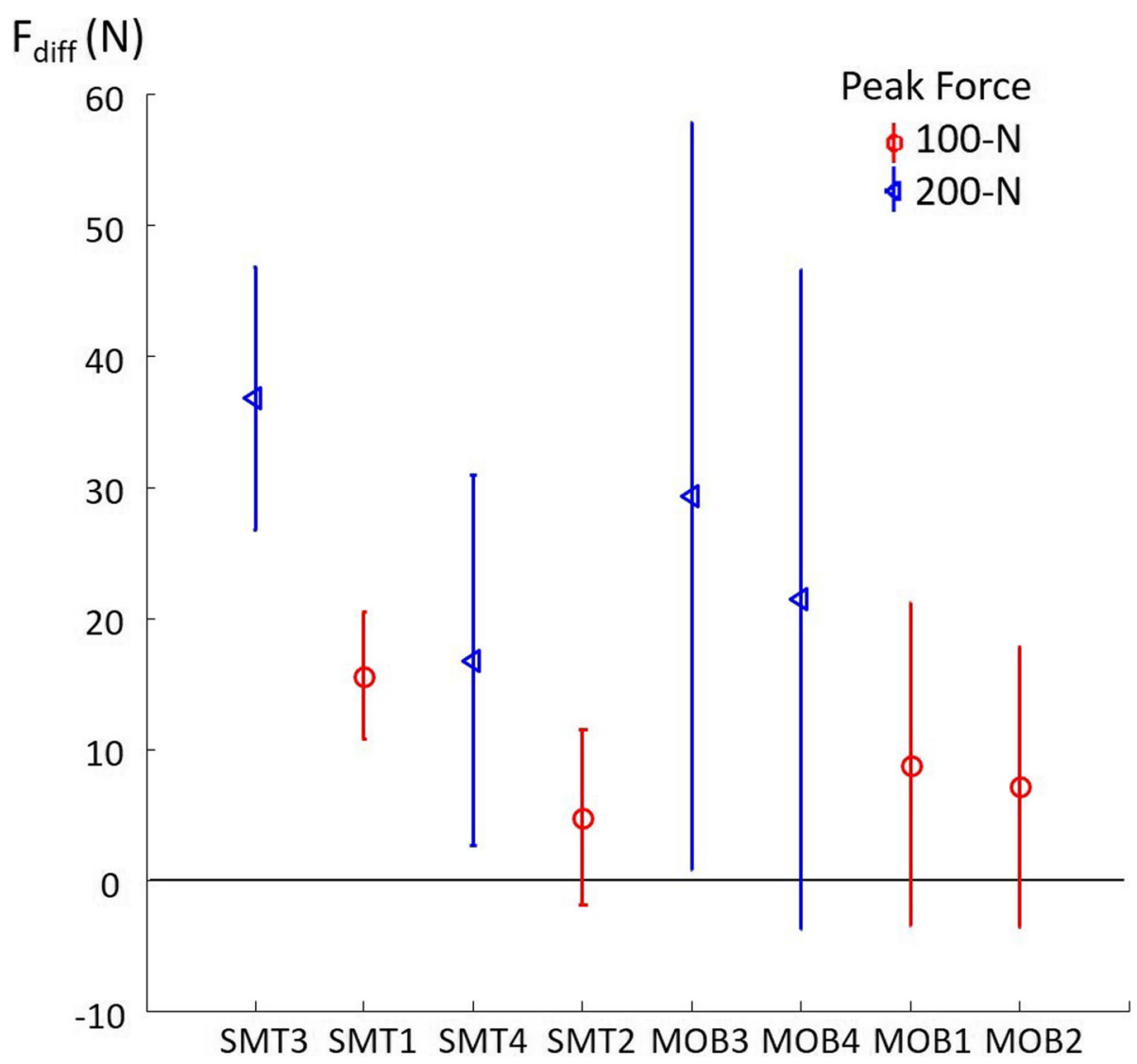

Fig. 3 Mean (with SD) $F_{\text {diff }}$ from the SMT with the higher rate of force application (SMT3) to the MOB with the lower rate of force application (MOB2). A significant linear trend was observed revealing a decrease in $F_{\text {diff }}$ with the decrease in rate of force application $(p<0.0001)$

\section{Discussion}

In this study, the difference between the force measured at the patient-table interface and the force applied at the clinician-patient interface during thoracic SMT and MOB delivered was assessed in asymptomatic adults. The effect of different SMT and MOB force-time characteristics and potential influencing factors were also assessed. It was hypothesized that the forces measured at the patient-table interface would be greater than those measured at the clinician-patient interface and that SMT and MOB characteristics, muscle activity and anthropometric variables would influence the difference between forces at both interfaces.

In this study, the force applied at the clinician-patient interface was provided via a servo-controlled linear actuator apparatus, thus reducing variability previously observed by different hand configuration during force application [21,22] and providing a systematic posterior to anterior force vector. Results showed that $93 \%$ of SMT and $84 \%$ of MOB yielded greater total peak forces at the patient-table interface. This was observed across the different SMT/MOB force-time profile. The average increase in force at the patient-table interface compared to the clinician-patient interface was $14.6 \%$. There was also a significant effect of the SMT/MOB thrust duration and total peak force on the difference between forces at both interfaces. Consequently, the rate of force application also had a significant effect on the difference in forces indicating that lower rate of force application decreases the difference between the forces measured at the patient-table and clinician-patient interfaces.

Why do we measure increased forces at patient-table interface? In 1999, Kirstukas and Backman (1999) [5] were the first to record simultaneously the magnitude of the resultant force vector at the supporting patient-table interface and the perpendicular contact pressure distribution at the clinician-patient interface.. The authors hypothesized that due to the gravitational loads, clinicianapplied loadings, and the accelerating patient's mass, the patient-table interface force magnitude during SMT would be higher than the forces applied at the clinicianpatient interface. However, their results showed the opposite as total peak forces at the clinician-patient interface exceeded total peak forces at the patient-table interface by $16 \%$. The results of our study differ from those of Kirstukas and Backman (1999) [5], as forces 
Table 5 Correlations ${ }^{1}$ between $\mathrm{F}_{\text {diff }}$ and potential influencing factors and differences between sex ${ }^{2}$

\begin{tabular}{|c|c|c|c|c|c|c|c|c|}
\hline Factors & SMT1 & SMT2 & SMT3 & SMT4 & MOB1 & MOB2 & MOB3 & MOB4 \\
\hline Sex & $\begin{array}{l}T_{32}=2.14 \\
p=0.04^{*}\end{array}$ & $\begin{array}{l}T_{32}=1.43 \\
p=0.16\end{array}$ & $\begin{array}{l}T_{32}=1.83 \\
p=0.08\end{array}$ & $\begin{array}{l}T_{32}=1.08 \\
p=0.29\end{array}$ & $\begin{array}{l}T_{32}=0.64 \\
p=0.53\end{array}$ & $\begin{array}{l}T_{32}=0.61 \\
p=0.55\end{array}$ & $\begin{array}{l}\mathrm{T}_{32}=0.20 \\
p=0.84\end{array}$ & $\begin{array}{l}T_{32}=0.81 \\
p=0.42\end{array}$ \\
\hline $\begin{array}{l}\text { Rod } \\
\text { displacement }\end{array}$ & $\begin{array}{l}r=0.67 \\
p=0.001^{*}\end{array}$ & $\begin{array}{l}r_{e}=0.30 \\
p=0.09\end{array}$ & $\begin{array}{l}r=0.54 \\
p=0.001^{*}\end{array}$ & $\begin{array}{l}r_{e}=0.05 \\
p=0.77\end{array}$ & $\begin{array}{l}r_{e}=-0.12 \\
p=0.51\end{array}$ & $\begin{array}{l}r_{e}=0.11 \\
p=0.55\end{array}$ & $\begin{array}{l}r_{e}=-0.17 \\
p=0.34\end{array}$ & $\begin{array}{l}r_{e}=-0.12 \\
p=0.49\end{array}$ \\
\hline Weight & $\begin{array}{l}r_{e}=-0.20 \\
p=0.26\end{array}$ & $\begin{array}{l}r_{e}=-0.27 \\
p=0.13\end{array}$ & $\begin{array}{l}r_{e}=-0.28 \\
p=0.11\end{array}$ & $\begin{array}{l}r_{e}=-0.32 \\
p=0.07\end{array}$ & $\begin{array}{l}r_{e}=-0.22 \\
p=0.21\end{array}$ & $\begin{array}{l}r_{e}=-0.24 \\
p=0.18\end{array}$ & $\begin{array}{l}r_{e}=-0.04 \\
p=0.82\end{array}$ & $\begin{array}{l}r_{e}=-0.08 \\
p=0.67\end{array}$ \\
\hline Height & $\begin{array}{l}r_{e}=-0.31 \\
p=0.08\end{array}$ & $\begin{array}{l}r_{e}=-0.29 \\
p=0.10\end{array}$ & $\begin{array}{l}r_{e}=-0.34 \\
p=0.05\end{array}$ & $\begin{array}{l}r_{e}=-0.24 \\
p=0.19\end{array}$ & $\begin{array}{l}r_{e}=-0.12 \\
p=0.52\end{array}$ & $\begin{array}{l}r_{e}=-0.08 \\
p=0.67\end{array}$ & $\begin{array}{l}r_{e}=0.08 \\
p=0.66\end{array}$ & $\begin{array}{l}r_{e}=0.14 \\
p=0.43\end{array}$ \\
\hline Age & $\begin{array}{l}r_{e}=0.18 \\
p=0.34\end{array}$ & $\begin{array}{l}r_{e}=0.16 \\
p=0.40\end{array}$ & $\begin{array}{l}r_{e}=0.05 \\
p=0.81\end{array}$ & $\begin{array}{l}r_{e}=-0.10 \\
p=0.58\end{array}$ & $\begin{array}{l}r_{e}=-0.29 \\
p=0.13\end{array}$ & $\begin{array}{l}r_{e}=0.17 \\
p=0.38\end{array}$ & $\begin{array}{l}r_{e}=-0.03 \\
p=0.89\end{array}$ & $\begin{array}{l}r_{e}=0.02 \\
p=0.91\end{array}$ \\
\hline BMI & $\begin{array}{l}r_{e}=-0.05 \\
p=0.79\end{array}$ & $\begin{array}{l}r_{e}=-0.17 \\
p=0.33\end{array}$ & $\begin{array}{l}r_{e}=-0.14 \\
p=0.43\end{array}$ & $\begin{array}{l}r_{e}=-0.27 \\
p=0.13\end{array}$ & $\begin{array}{l}r_{e}=-0.23 \\
p=0.19\end{array}$ & $\begin{array}{l}r_{e}=-0.29 \\
p=0.10\end{array}$ & $\begin{array}{l}r_{e}=-0.12 \\
p=0.50\end{array}$ & $\begin{array}{l}r_{e}=-0.23 \\
p=0.21\end{array}$ \\
\hline $\begin{array}{l}\text { Percentage of } \\
\text { body fat }\end{array}$ & $\begin{array}{l}r_{e}=0.33 \\
p=0.06\end{array}$ & $\begin{array}{l}r_{e}=0.23 \\
p=0.19\end{array}$ & $\begin{array}{l}r_{e}=0.27 \\
p=0.13\end{array}$ & $\begin{array}{l}r_{e}=0.21 \\
p=0.25\end{array}$ & $\begin{array}{l}r_{e}=0.09 \\
p=0.61\end{array}$ & $\begin{array}{l}r_{e}=-0.06 \\
p=0.75\end{array}$ & $\begin{array}{l}r_{e}=-0.03 \\
p=0.86\end{array}$ & $\begin{array}{l}r_{e}=-0.15 \\
p=0.39\end{array}$ \\
\hline $\begin{array}{l}\text { Percentage of } \\
\text { trunk fat }\end{array}$ & $\begin{array}{l}r_{e}=0.34 \\
p=0.06\end{array}$ & $\begin{array}{l}r_{e}=0.19 \\
p=0.30\end{array}$ & $\begin{array}{l}r_{e}=0.25 \\
p=0.16\end{array}$ & $\begin{array}{l}r_{e}=0.16 \\
p=0.38\end{array}$ & $\begin{array}{l}r_{e}=0.09 \\
p=0.62\end{array}$ & $\begin{array}{l}r_{e}=-0.10 \\
p=0.57\end{array}$ & $\begin{array}{l}r_{e}=-0.05 \\
p=0.77\end{array}$ & $\begin{array}{l}r_{e}=-0.13 \\
p=0.46\end{array}$ \\
\hline Thickness & $\begin{array}{l}r_{e}=-0.01 \\
p=0.97\end{array}$ & $\begin{array}{l}r_{e}=-0.36 \\
p=0.049^{*}\end{array}$ & $\begin{array}{l}r_{e}=-0.02 \\
p=0.90\end{array}$ & $\begin{array}{l}r_{e}=-0.21 \\
p=0.27\end{array}$ & $\begin{array}{l}r_{e}=-0.35 \\
p=0.06\end{array}$ & $\begin{array}{l}r_{e}=-0.53 \\
p=0.004^{*}\end{array}$ & $\begin{array}{l}r_{e}=-0.19 \\
p=0.32\end{array}$ & $\begin{array}{l}r_{e}=-0.28 \\
p=0.13\end{array}$ \\
\hline T5 nRMS & $\begin{array}{l}r_{e}=-0.03 \\
p=0.88\end{array}$ & $\begin{array}{l}r_{e}=0.07 \\
p=0.72\end{array}$ & $\begin{array}{l}r_{e}=-0.05 \\
p=0.80\end{array}$ & $\begin{array}{l}r_{e}=0.50 \\
p=0.01^{*}\end{array}$ & $\begin{array}{l}r_{e}=-0.08 \\
p=0.70\end{array}$ & $\begin{array}{l}r_{e}=0.22 \\
p=0.26\end{array}$ & $\begin{array}{l}r_{e}=0.23 \\
p=0.22\end{array}$ & $\begin{array}{l}r_{e}=0.24 \\
p=0.20\end{array}$ \\
\hline T7 nRMS & $\begin{array}{l}r_{\mathrm{e}}=0.15 \\
p=0.44\end{array}$ & $\begin{array}{l}r_{e}=0.08 \\
p=0.67\end{array}$ & $\begin{array}{l}r=-0.07 \\
p=0.71\end{array}$ & $\begin{array}{l}r_{e}=0.44 \\
p=0.02^{*}\end{array}$ & $\begin{array}{l}r_{e}=0.07 \\
p=0.72\end{array}$ & $\begin{array}{l}r_{e}=0.15 \\
p=0.53\end{array}$ & $\begin{array}{l}r_{e}=0.42 \\
p=0.02^{*}\end{array}$ & $\begin{array}{l}r_{e}=0.11 \\
p=0.56\end{array}$ \\
\hline
\end{tabular}

* Significant correlation / difference at $p<0.05$

1 Pearson correlation coefficient $(r)$ or its estimated value from Kendall Tau rank coefficient $\left(r_{\mathrm{e}}\right)$ are presented. Positive correlation value denotes an increase in $\mathrm{F}_{\text {diff }}$ with the increase in the factor value

${ }^{2}$ Positive T-test value denotes greater $F_{\text {diff }}$ in females

recorded at the patient-table interface were generally higher than the forces applied at the clinician-patient interface by the apparatus. Not only do they differ, but they seem to support the hypothesis that near-static loading of the spine (MOB) yields different force patterns than higher rate of force application procedures (SMT). Indeed, differences between forces recorded at the patient-table interface and forces applied at the clinician-patient interface are much lower when lower rates of force application are used.

How do SMT/MOB force-time profile alter the difference between the force at the patient-table and the clinician-patient interfaces? Rate of force application and other SMT/MOB characteristics can modulate mechanical and neurophysiological responses generated during and following the technique application. For instance, the muscular response amplitude seems to increase with higher total peak force [12, 23, 24]. When thrust duration and total peak force were modulated while keeping a constant rate of force application, there was no difference observed in muscular response amplitude [25]. In animal studies, muscle spindle activity was amplified by either shorter thrust duration or higher total peak force during SMT [26-31]. Some animal studies even showed both, corresponding to a higher rate of force application [2628]. Vertebral displacement also seems to be modulated by different SMT characteristics. Greater vertebral displacement is associated with increased total force applied at the clinician-patient interface [23, 25, 32]. Greater absolute vertebral displacement and lower relative displacement (i.e. displacement between two adjacent vertebrae) are also observed when MOB thrust durations are compared to SMT's thrust durations [10]. In the present study, significant changes in the differences in forces at the patient-table and clinician-patient interfaces were observed when rate of force application was modulated. The observed changes support the hypothesis that higher rates of force application increase the difference between the forces at patient-table and clinician-patient interfaces.

None of the measured potential influencing factors was found to be associated with the difference between the forces at the clinician-patient and patient-table interfaces through all the eight SMT and MOB force-time profiles. Sex of the participant, apparatus displacement, thoracic thickness and muscle activity did show a significant correlation through only one or two set of SMT and/or MOB force-time profiles. These results did not confirm our initial hypothesis proposing that anthropometry would influence the difference between the forces at the patient-table and clinician-patient interfaces [33, 34].

\section{Strengths and limitations}

The main strength of this study is the more precise measurement of the forces at both the patient-table and 
clinician-patient interfaces. Moreover, the use of an apparatus to deliver the SMT and MOB force-time profiles allowed the evaluation of the effect of the SMT and MOB characteristics on the difference between the forces at both interfaces. Limitations include the sample size limited to 33 participants as well as the used of a convenient sample of healthy young adults without spine related pain. Therefore, results might not apply to people with thoracic pain, pediatric patients or older adults. Considering the exploratory nature of the correlation analyses, corrections for multiple analyses were not computed. The observed significant correlations should therefore be interpreted with cautious. While a similar study with SMT and MOB being applied by a clinician has been conducted (manuscript under review), the extrapolation of this study's results is currently limited. Indeed, manual therapy application configuration has been shown to influence the magnitude, location, and distribution of the pressure generated [35]. Consequently, the current study results might not be representative of manually applied SMT/MOB or of apparatusbased studies using other type of application.

\section{Clinical implications}

The exploratory nature of this study limits the application of our results into clinical practice at this point. While results from this study suggest that anthropometric characteristics and muscle activation do not influence on the difference between the forces at the patient-table and clinician-patient interfaces, other potential influencing factors such as kyphosis degree and tissue stiffness should be investigated. Indeed, it has been described that structures with higher stiffness stress-shield adjacent tissues during movement [36] and future studies are planned to elucidate this. Most importantly, this study highlights the significance of the specific methods to measure the force-time characteristics during manual therapies as well as the limitations of comparing studies that use different methods of force measurement. Consequently, comparing manual therapy force-time characteristics measured at the patient-table interface with the ones measured at the clinician-patient interface is not recommended.

\section{Conclusion}

This study revealed that, during thoracic manual therapy (SMT and MOB), forces measured at the patient-table interface are most often greater than forces applied at the clinician-patient interface. Moreover, manual therapy characteristics (total peak force, thrust duration and rate of force application) influence the difference of forces between the interfaces. Whether individual characteristics influence the transmission of force still needs to be further investigated. The results therefore suggest that manual therapy force-time profiles measured at the patient-table interface should not be compared to profiles measured at the clinician-patient interface.

\begin{abstract}
Abbreviations
BMI: Body mass index; EMG: Electromyography; $F_{\text {diff: Difference between }}$ forces at the patient-table interface and at the clinician-patient interface; $\mathrm{F}_{\text {PTint }}$ : Force at the patient-table interface; FSTT ${ }^{\bullet}$ : Force sensing table technology; IQR: Inter-quartile range; MOB: Spinal mobilization; RMS: Root mean square; nRMS: Normalized root mean square; SD: Standard deviation; SMT: Spinal manipulative therapy; TES: Thoracic erector spinae
\end{abstract}

\section{Acknowledgements}

Not applicable.

\section{Authors' contributions}

MF, MD and IP were involved with concept development and designed the study. JM and IP collected data. All authors were involved with data analysis and interpretation as well as significant contributors to writing the manuscript and approved the final manuscript.

\section{Funding}

Funding for this study was provided by the Chaire de recherche internationale en santé neuromusculosquelettique and its partner the Fondation chiropratique du Québec. The funding sources had no role in study design, in the collection, analysis and interpretation of data, in the writing of the report and in the decision to submit the article for publication.

\section{Availability of data and materials}

The datasets used and analysed during the current study are available from the corresponding author on reasonable request.

\section{Ethics approval and consent to participate}

This study was reviewed and approved by the Université du Québec à TroisRivières human research ethics committee (CER-19-257-07.19) and all participants provided their written informed consent prior to participating in the study.

\section{Consent for publication}

Not applicable.

\section{Competing interests}

The authors declare that they have no competing interests.

\section{Author details}

1Department of Chiropractic, Université du Québec à Trois-Rivières, 3351 boul. Des Forges, Trois-Rivières G8Z 4M3, Québec, Canada. ²Division of Research and Innovation, Canadian Memorial Chiropractic College, 6100 Leslie St, Toronto, Ontario M2H 3J1, Canada. ${ }^{3}$ Department of Human Kinetics, Université du Québec à Trois-Rivières, 3351 boul. Des Forges, Trois-Rivières G8Z 4M3, Québec, Canada. ${ }^{4}$ Center for Interdisciplinary Research in Rehabilitation and Social Integration (CIRRIS), 25 Wilfrid-Hamel Blvd., Québec G1M 2S8, Québec, Canada.

Received: 7 June 2020 Accepted: 19 October 2020

Published online: 10 November 2020

\section{References}

1. Beliveau PJH, Wong JJ, Sutton DA, Simon NB, Bussieres AE, Mior SA, French SD. The chiropractic profession: a scoping review of utilization rates, reasons for seeking care, patient profiles, and care provided. Chiropr Man Therap. 2017;25:35.

2. Herzog W. The biomechanics of spinal manipulation. J Bodyw Mov Ther. 2010;14:280-6.

3. Herzog W, Conway PJ, Kawchuk GN, Zhang Y, Hasler EM. Forces exerted during spinal manipulative therapy. Spine. 1993;18:1206-12.

4. Pickar JG, Bolton PS. Spinal manipulative therapy and somatosensory activation. J Electromyogr Kinesiol. 2012;22:785-94.

5. Kirstukas SJ, Backman JA. Physician-applied contact pressure and table force response during unilateral thoracic manipulation. J Manip Physiol Ther. 1999;22:269-79. 
6. Triano J, Schultz AB. Loads transmitted during lumbosacral spinal manipulative therapy. Spine. 1997;22:1955-64.

7. Snodgrass SJ, Rivett DA, Robertson VJ. Manual forces applied during posterior-to-anterior spinal mobilization: a review of the evidence. J Manip Physiol Ther. 2006;29:316-29.

8. Downie AS, Vemulpad S, Bull PW. Quantifying the high-velocity, lowamplitude spinal manipulative thrust: a systematic review. J Manip Physiol Ther. 2010;33:542-53.

9. Descarreaux M, Nougarou F, Dugas C. Standardization of spinal manipulation therapy in humans: development of a novel device designed to measure dose-response. J Manip Physiol Ther. 2013;36:78-83.

10. Page I, Biner E, Descarreaux M. Vertebral displacements and muscle activity during manual therapy: distinct behaviors between spinal manipulation and mobilization. J Manip Physiol Ther. 2018;41:753-61.

11. Pagé I, Nougarou F, Dugas C, Descarreaux M. The effect of spinal manipulation impulse duration on spine neuromechanical responses. J Can Chiropr Assoc. 2014:58:141-8.

12. Nougarou F, Dugas C, Deslauriers C, Page I, Descarreaux M. Physiological responses to spinal manipulation therapy: investigation of the relationship between electromyographic responses and peak force. J Manip Physiol Ther. 2013:36:557-63.

13. Nougarou N, Dugas C, Loranger M, Pagé I, Descarreaux M. The role of preload forces in spinal manipulation: experimental investigation of kinematic and Electromyographic responses in healthy adults. J Manipulative Physiol Ther. 2014;37:287-93.

14. Rogers $\mathrm{CM}$, Triano JJ. Biomechanical measure validation for spinal manipulation in clinical settings. J Manip Physiol Ther. 2003;26:539-48.

15. World Health $\mathrm{O}$. WHO guidelines on basic training and safety in chiropractic. In Book WHO guidelines on basic training and safety in chiropractic (editor ed.^eds.). City: World Health Organization; 2005.

16. Cooperstein R, Haneline MT, Young MD. The location of the inferior angle of the scapula in relation to the spinal level of prone patients. J Can Chiropr Assoc. 2009;53:121-8.

17. Pagé I, Descarreaux M, Sobczak S. Development of a new palpation method using alternative landmarks for the determination of thoracic transverse processes: an in vitro study. Musculoskelet Sci Pract. 2017;27:142-9.

18. Kuntz C 4th, Levin LS, Ondra SL, Shaffrey Cl, Morgan CJ. Neutral upright sagittal spinal alignment from the occiput to the pelvis in asymptomatic adults: a review and resynthesis of the literature. J Neurosurg Spine. 2007; 6(2):104-12. https://doi.org/10.3171/spi.2007.6.2.104. PMID: 17330576.

19. Bijur PE, Silver W, Gallagher EJ. Reliability of the visual analog scale for measurement of acute pain. Acad Emerg Med. 2001;8:1153-7.

20. Hazra A, Gogtay N. Biostatistics series module 6: correlation and linear regression. Indian J Dermatol. 2016;61:593-601.

21. Perle SM, Kawchuk GN. Pressures Generated During Spinal Manipulation and Their Association With Hand Anatomy. J Manipulative Physiol Ther. 2005;28:265.e261-7.

22. Herzog W, Kats M, Symons B. The effective forces transmitted by highspeed, low-amplitude thoracic manipulation. Spine. 2001;26:2105-10.

23. Colloca CJ, Keller TS, Gunzburg R. Neuromechanical characterization of in vivo lumbar spinal manipulation. Part II. Neurophysiological response. J Manipulative Physiol Ther. 2003;26(9):579-91. https://doi.org/10.1016/j.jmpt. 2003.08.004. PMID: 14673407.

24. Pagé I, Nougarou F, Descarreaux M. Neuromuscular response amplitude to mechanical stimulation using large-array surface electromyography in participants with and without chronic low back pain. J Electromyogr Kinesiol. 2016;27:24-9. https://doi.org/10.1016/j.jelekin.2016.01.004. Epub 2016 Jan 28. PMID: 26874078

25. Nougarou F, Pagé I, Loranger M, Dugas C, Descarreaux M. Neuromechanical response to spinal manipulation therapy: effects of a constant rate of force application. BMC Complement Altern Med. 2016;16:161.

26. Pickar JG, Kang YM. Paraspinal muscle spindle responses to the duration of a spinal manipulation under force control. J Manip Physiol Ther. 2006;29

27. Pickar JG, Sung PS, Kang YM, Ge W. Response of lumbar paraspinal muscles spindles is greater to spinal manipulative loading compared with slower loading under length control. Spine J. 2007;7(5):583-95. https://doi.org/10. 1016/j.spinee.2006.10.006. Epub 2007 Jan 10. PMID: 17905321; PMCID: PMC2075482

28. Reed WR, Cao DY, Long CR, Kawchuk GN, Pickar JG. Relationship between biomechanical characteristics of spinal manipulation and neural responses in an animal model: effect of linear control of thrust displacement versus force, thrust amplitude, thrust duration, and thrust rate. Evid Based Complement Alternat Med. 2013;2013:492039.

29. Reed WR, Liebschner MA, Sozio RS, Pickar JG, Gudavalli MR. Neural response during a mechanically assisted spinal manipulation in an animal model: a pilot study. J Nov Physiother Phys Rehabil. 2015;2:20-7.

30. Reed WR, Long CR, Kawchuk GN, Pickar JG. Neural responses to the mechanical parameters of a high-velocity, low-amplitude spinal manipulation: effect of preload parameters. J Manip Physiol Ther. 2014;37.

31. Reed WR, Pickar JG, Sozio RS, Liebschner MAK, Little JW, Gudavalli MR. Characteristics of Paraspinal muscle spindle response to mechanically assisted spinal manipulation: a preliminary report. J Manipulative Physio Ther. 2017;40(6):371-80. https://doi.org/10.1016/j.jmpt.2017.03.006. Epub 2017 Jun 17. PMID: 28633885; PMCID: PMC5679286.

32. Colloca CJ, Keller TS, Gunzburg R. Biomechanical and neurophysiological responses to spinal manipulation in patients with lumbar radiculopathy. J Manipulative Physiol Ther. 2004;27(1):1-15. https://doi.org/10.1016/j.jmpt. 2003.11.021. PMID: 14739869.

33. Saini K, Kumar N. Mechanical response of collagen molecule under hydrostatic compression. Mater Sci Eng C. 2015;49:720-6.

34. Comley K, Fleck N. The compressive response of porcine adipose tissue from low to high strain rate. Int J Impact Eng. 2012;46:1-10.

35. Perle SM, Kawchuk GN. Pressures generated during spinal manipulation and their association with hand anatomy. J Manip Physiol Ther. 2005;28:e1-7.

36. Peterson JM, Chlebek C, Clough AM, Wells AK, Ledet EH. Stiffness matters: part l-the effects of plate stiffness on the biomechanics of ACDF: in vitro. Spine. 2018;43:E1061-8.

\section{Publisher's Note}

Springer Nature remains neutral with regard to jurisdictional claims in published maps and institutional affiliations.

Ready to submit your research? Choose BMC and benefit from:

- fast, convenient online submission

- thorough peer review by experienced researchers in your field

- rapid publication on acceptance

- support for research data, including large and complex data types

- gold Open Access which fosters wider collaboration and increased citations

- maximum visibility for your research: over $100 \mathrm{M}$ website views per year

At BMC, research is always in progress.

Learn more biomedcentral.com/submissions 